\title{
COMPARISON OF TWO STRATEGIES FOR SURFACTANT PROPHYLAXIS IN PREMATURE INFANTS: PRELIMINARY DATA OF A RANDOMIZED TRIAL
}

\author{
E. Okulu, S. Arsan, I. Mungan Akin, B. Atasay, S. Alan, A. Kılıç, T. Turmen
}

Ankara University, Ankara, Turkey

Objective: The purpose of this study is to determine whether the immediate bolus strategy combined with early nasal CPAP treatment can decrease the need of subsequent invasive ventilation compared with the administration of surfactant prophylaxis at 15 minutes after birth with early nasal CPAP application.

Methods: Infants born either before 28 weeks' or at 29-30 weeks' who did not receive antenatal steroids were randomized before delivery. Infants randomized to group-1 were intubated immediately after birth and administered $100 \mathrm{mg} / \mathrm{kg}$ surfactant and then initiated standard CPR as indicated. Infants randomized to the group-2 were intubated electively at 15 minutes after birth and received $100 \mathrm{mg} / \mathrm{kg}$ surfactant after resuscitation and initial stabilization. T-piece system was used during these interventions. After surfactant treatment, all infants were extubated to nCPAP. Infants possesing predefined criteria were intubated for mechanical ventilation (MV).

Results: Group-1 ( $\mathrm{n}=15)$ and group-2 $(\mathrm{n}=10)$ had similar demographic and clinical characteristics. In each group there was an infant who could not be extubated and another one who needed MV. Median hours on nCPAP were 10 (1-93) in group-1 and $14(2-96)$ in group-2 $(\mathrm{p}=0.64)$. There were no significant differences between the groups with respect to mortality, hospital stay, and the secondary outcomes; pneumothorax, pulmonary hemorrhage, PDA, NEC, ROP, IVH, use of systemic postnatal corticosteroids, and oxygen requirement at postnatal 28 days of life.

Conclusion: Our preliminary data, demonstrates that immediate bolus strategy of surfactant prophylaxis is not superior to administration of surfactant prophylaxis at 15 minutes after birth combined with early nasal CPAP. 